\title{
Experimental study on seismic behavior of shear wall with fiber reinforced polymer concrete
}

\author{
Xing-yu SONG* Qin HOU Lei CHEN \\ Yang Zhou University, Huayang road 198,Yangzhou,225000,China
}

\begin{abstract}
In order to improve the seismic performance of common concrete shear wall with concealed bracings, fiber reinforced polymer modified concrete instead of ordinary concrete was applied to the shear wall as described in this paper. In this paper, the experimental study on the seismic performance of two different types of shear walls under cyclic loading was carried out, and also the failure characteristics, bearing capacity, ductility, hysteretic curve, stiffness attenuation and energy dissipation performance of the proposed shear wall were analyzed systematically. The test results show that the seismic performance of fiber-reinforced polymer modified concrete shear wall is significantly improved because its the damping ratio, deformation capacity and energy dissipation capacity are greatly improved compared with ordinary concrete shear wall with concealed bracings, which ensures its better stiffness stability in the later stage .
\end{abstract}

Key words: Fiber reinforced polymer modified concrete; shear wall with concealed bracings; low cyclic loading test; seismic performance

The reinforced concrete shear wall is a lateral resisting component formed by the organic combination of steel and concrete. Theoretically, there are two ways to improve the seismic ability of shear walls including modifying its steel structure and improving the concrete performance. In recent decades, modifying the steel structure of the shear wall as a new technology is coming to our sight. A large number of experiments have shown that for medium and high reinforced concrete shear walls[1][2][3], their seismic bearing capacity, energy dissipation and deformability can be remarkably improved by setting concealed bracings. The failure mode can be improved to some extent. However, the introduction of concealed bracings does not delay the cracking of the shear wall because of the brittle quality of concrete. Therefore, the cracking mode and failure mechanism of the reinforced concrete shear wall with concealed bracings still have room for improvement.

Fiber reinforced polymer concrete is a kind of composite material with high performance obtained by adding a certain proportion of polymer and fiber admixture into the concrete. Experimental research shows that compared with ordinary concrete[4]-[10], although with higher cracking resistance, fiber reinforced polymer concrete is characterized by higher energy dissipation, greater deformation capacity and better tenacity. Thus, the ductility and damping of the components which are made of it can be enhanced. In order to improve the seismic performance of the reinforced concrete shear wall with concealed bracings, this paper focuses on the application of fiber-reinforced polymer shear wall composed of fiber reinforced polymer concrete.

In order to prove the feasibility and rationality of the reinforcement scheme of fiber reinforced polymer concrete shear walls with concealed bracings and new low shear walls, this paper has completed two quasistatic tests on high shear walls ( one ordinary concrete shear wall and one fiber reinforced polymer concrete shear walls) with concealed bracings. The failure modes, bearing capacity, hysteresis curve, stiffness degradation and energy dissipation capacity of two shear walls under low cycle reciprocating load were obtained. The effects of shear span ratio and axial compression ratio on the seismic performance of shear walls were also examined.

\section{Overview.}

\subsection{Model design}

In this paper, two shear walls were designed. They have the same reinforcement with the span ratio of 2 numbered as HSW, HDHSW. The thickness of the two shear walls is $100 \mathrm{~mm}$. Except for HSW composed of common concrete, the other is made of fiber-reinforced polymer concrete. Sizes and reinforcements of the shear walls are detailed in Figure 1 and Table 1.

\footnotetext{
*Xing-yu SONG : ppsxy@163.com
} 


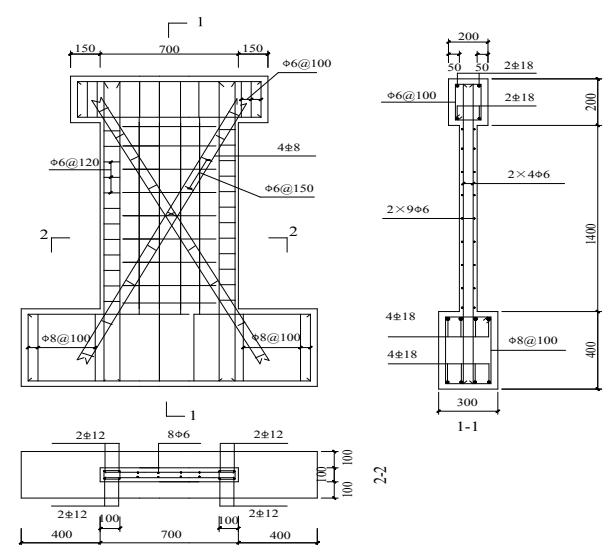

Fig.1.Reinforcement details of specimens

Table.1. Parameters of specimens

\begin{tabular}{|c|c|c|}
\hline Sample number & HSW & HDHSW \\
\hline Shear span ratio & 2 & 2 \\
\hline Wall height $(\mathrm{mm})$ & 1400 & 1400 \\
\hline Wallboard width $(\mathrm{mm})$ & 700 & 700 \\
\hline Concealed column $(\mathrm{mm})$ & $100 \times 100$ & $100 \times 100$ \\
\hline Reinforcement situation & See in Fig.1 & See in Fig.1 \\
\hline Axial load $(\mathrm{kN})$ & 233.8 & 233.8 \\
\hline axial compression ratio & 0.2 & 0.2 \\
\hline
\end{tabular}

\subsection{Material properties}

In the experiment, the shear wall HSW used for comparison is constructed by ordinary $\mathrm{C} 35$ concrete. The compressive strength of the $\mathrm{C} 35$ ordinary concrete prism is $33.2 \mathrm{MPa}$, and the elastic modulus is $3.25 \times 10^{4} \mathrm{MPa}$. Based on the previous study [11], the fiber-reinforced polymer concrete is made by adding $12 \%$ by mass of cement mixture of styrene-acrylic emulsion and carboxylated styrene-butadiene latex, together with polypropylene fiber with a volume content of $0.2 \%$ into the concrete. After trials, it was finally determined that when the mixture ratio of cement: sand: gravel: water $=1: 1.27: 2.31: 0.41$, the compressive strength of the concrete prism is $34.1 \mathrm{MPa}$, which is closed to $33.2 \mathrm{MPa}$. So the ratio was applied to the experiment. The elastic modulus of fiber reinforced polymer concrete is tested as $3.06 \times 10^{4} \mathrm{MPa}$. The properties of steel can be seen in Table 2.

Table.2. Properties of reinforcing bars

\begin{tabular}{|c|c|c|c|}
\hline Specifications & $\begin{array}{c}\text { Yield } \\
\text { strength } \\
(\mathrm{MPa})\end{array}$ & $\begin{array}{c}\text { ultimate } \\
\text { strength } \\
(\mathrm{MPa})\end{array}$ & $\begin{array}{c}\text { Modulus of } \\
\text { elasticity } \\
(\mathrm{MPa})\end{array}$ \\
\hline$\Phi 6$ & 458 & 542 & $2.01 \times 10^{5}$ \\
\hline$\Phi 8$ & 407 & 477 & $2.07 \times 10^{5}$ \\
\hline$\Phi 10$ & 416 & 461 & $2.03 \times 10^{5}$ \\
\hline$\Phi 12$ & 396 & 547 & $2.05 \times 10^{5}$ \\
\hline$\Phi 14$ & 385 & 518 & $2.03 \times 10^{5}$ \\
\hline$\Phi 18$ & 380 & 527 & $2.01 \times 10^{5}$ \\
\hline
\end{tabular}

\subsection{Test equipment and loading system}

The test included two parts: dynamic test and pseudostatic test. The dynamic test was carried out before and after the loading of the specimen, so as to get the change of frequency and damping of the specimens. The pseudo static test is used in low cycle repeated loading. The test device is shown in Figure 2. The foundation beam was settled on the test platform through anchor beams and ground anchor; loading beam was connected to the end of a horizontal jack in one side through screw and end plate. The rigid distribution beam was placed at the top of the specimen, so that the pressure of the jack shaft is evenly distributed to the wall, thus the stress state of the specimen is closer to the engineering practice. A roller was set between the vertical jack and the beam to ensure that the vertical jack can move along with the top side of the test piece.

Horizontal loading process was in accordance with the force-displacement control method[11]: based on the force control, the loading process was divided into three levels with each cycled once in elastic stage: when the peak force displacement curve of the specimens appeared, we began the loading process step by step with displacement control. The displacement of mid-rise shear walls was $5 \mathrm{~mm}$ while that of the two low shear walls was $3 \mathrm{~mm}$. In this stage, each load level was cycled twice. The test ended when the load level decreased to $85 \%$ of its peak.

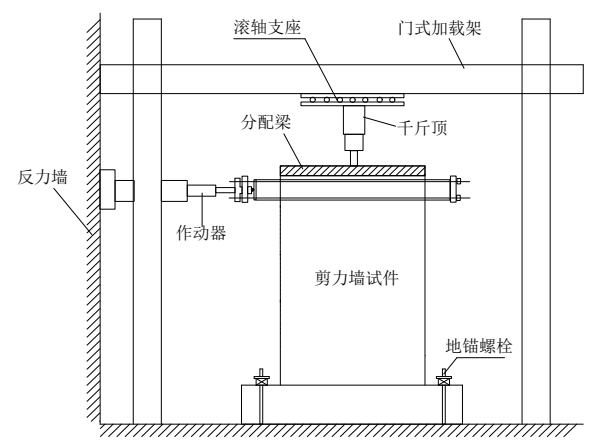

Fig.2. Test setup

\subsection{Test content}

The physical quantity of the specimens including load, displacement, relative deformation and strain were measured during the test. A displacement meter was settled in the center of the loading beam to measure the top displacement; one horizontal displacement meter and two vertical displacement meters were placed on the foundation beam to measure and revise the displacement of the specimens caused by the translation and rotation of the foundation beam; constant monitor of the vertical load was applied to keep the axial pressure steady. In addition, a number of strain gauges were arranged in the specimens to exam the plastic development of the walls. 


\section{Test results and analysis}

\subsection{Failure process and its patterns}

The failure patterns of each shear wall are shown in Figure 3. After analysis, the failure process of each specimen has the following characteristics:

For two high shear walls, the horizontal cracks first appear on the bottom of the wall when the cracking load is reached. As the load increases, the cracks gradually move upward, and extend to sides. Keep increasing load results in several cracks. When the load reaches the limit, the slant cracks speed up. And the deformation rate gains its speed after the cracks reach the neutral axis. When it comes to the final failure, the concrete in the two sides of the root is crushed leaving the whole specimen destructed and bended. As the Figure 3 shows, when destructed, cracks mainly spread in the lower $1 / 3$ part of the shear wall HSW with common concrete while the cracks distribute wider in the shear wall HDHSW with fiber-reinforced polymer concrete. At the same time, compared with HSW, the crushing zone at the bottom of HDHSW is smaller, indicating that the damage of the shear wall with fiber-increased polymer concrete is smaller.

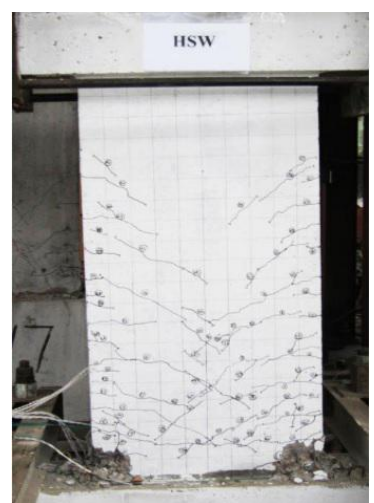

(a) HSW

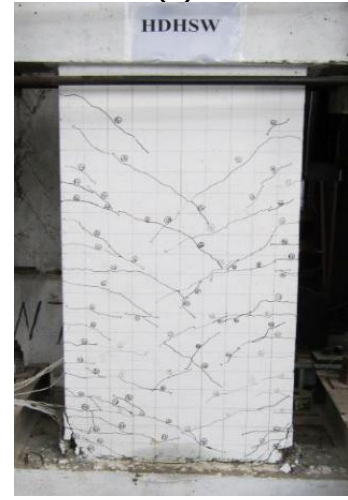

(b) HDHSW

Fig.3. Crack failure patterns of 2 specimens

\subsection{Bearing capacity and ductility analysis}

In Table 3, the measured values of the cracking load, the obvious yield load and the ultimate load of the two single - limb shear walls are given in this experiment. The top displacements and their ductility of two shear walls are given in Table $4 . F_{\mathrm{c}}$ and $U_{\mathrm{c}}$ are the mean cracking load and displacement; $F_{\mathrm{y}}$ and $U_{\mathrm{y}}$ are the sharp yield load and yield displacement calculated according to the principle of conservation of energy; $F \mathrm{~m}$ is the maximum horizontal load; $U_{\mathrm{d}}$ is the maximum elastic plastic displacement value before the load drop obviously; $\mu_{\mathrm{cm}}$ is the ratio of cracking load to the ultimate load; $\mu_{\mathrm{ym}}$ is the ratio of yield load to the ultimate load; $\mu$ is ductility factor

Table.3. Experimental results of bearing capacity of specimens

\begin{tabular}{|c|c|c|c|}
\hline \multicolumn{2}{|c|}{ Sample number } & HSW & HDHSW \\
\hline \multirow{2}{*}{$F_{\mathrm{c} / \mathrm{kN}}$} & positive & 25.2 & 30.1 \\
\cline { 2 - 4 } & negative & -26.3 & -32.1 \\
\hline \multirow{2}{*}{$F_{\mathrm{y} / \mathrm{kN}}$} & positive & 100.5 & 113.4 \\
\cline { 2 - 4 } & negative & -98.7 & -117.2 \\
\hline$F_{\mathrm{m} / \mathrm{kN}}$ & positive & 163.5 & 175.1 \\
\cline { 2 - 4 } & negative & -157.3 & -172.2 \\
\hline $\begin{array}{c}\mu_{\mathrm{cm}} \\
\text { Mean value }\end{array}$ & $F_{\mathrm{c}} / F_{\mathrm{m}}$ & 0.16 & 0.18 \\
\hline $\begin{array}{c}\mu_{\mathrm{ym}} \\
\text { Mean valure }\end{array}$ & $F_{\mathrm{y}} / F_{\mathrm{m}}$ & 0.62 & 0.66 \\
\hline
\end{tabular}

Table.4. Experimental results of displacements and ductility factors of specimens

\begin{tabular}{|c|c|c|c|}
\hline \multicolumn{2}{|c|}{ Sample number } & HSW & HDHSW \\
\hline \multirow{2}{*}{$U_{\mathrm{c}} / \mathrm{mm}$} & positive & 1.1 & 1.48 \\
\cline { 2 - 4 } & negative & -1.2 & -1.52 \\
\hline \multirow{2}{*}{$U_{\mathrm{y}} / \mathrm{mm}$} & positive & 7.21 & 7.71 \\
\cline { 2 - 4 } & negative & -7.45 & -7.94 \\
\hline \multirow{2}{*}{$U_{\mathrm{d}} / \mathrm{mm}$} & positive & 33.19 & 39.21 \\
\cline { 2 - 4 } & negative & -33.55 & -40.3 \\
\hline \multirow{2}{*}{$\mu$ mean value } & $U_{\mathrm{d}} / U_{\mathrm{y}}$ & 4.55 & 5.08 \\
\hline
\end{tabular}

It can be seen from the above two tables that:

Compared with common shear walls with concealed bracings, the cracking load, ultimate load, deformation capacity and ductility of fiber-reinforced polymer concrete shear walls are all been greatly improved by $8.3 \%, 30.4 \%, 19.2 \%$ and $11.6 \%$ respectively, which prove that the fiber reinforced polymer concrete has good effect on improving the seismic performance of shear walls.

\subsection{Hysteresis analysis and comparison of skeleton curves}

The hysteresis curves and skeleton curves of two shear walls are given respectively in Figure 4 and Figure 5. The hysteresis curve can reflect the strength, stiffness, deformability and energy dissipation of shear walls. From Figure 4, it can be seen that the hysteretic curve of shear wall HDHSW is plumper than that of HSW. In addition, the bearing capacity of the shear wall drops slightly when the structure of the wall is destroyed. This relatively better stability in bearing capacity proves that 
the fiber-reinforced concrete shear walls have better energy dissipation capacity.

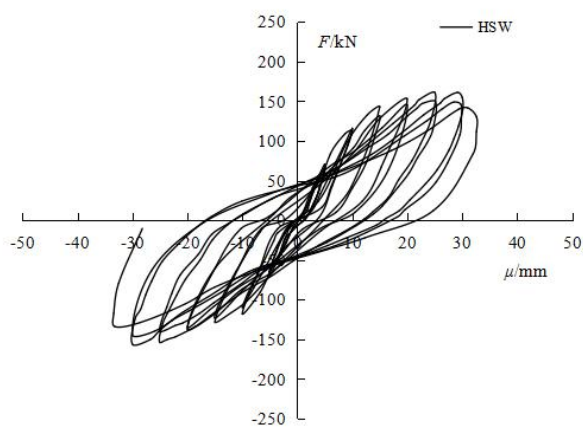

(a) HSW

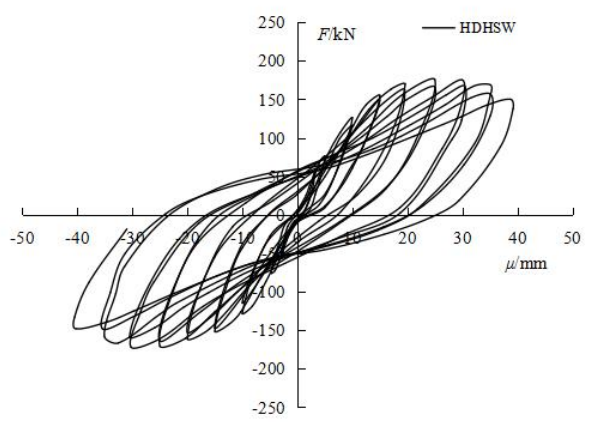

(b) HDHSW

Fig.4. The contrast diagram of hysteretic curves

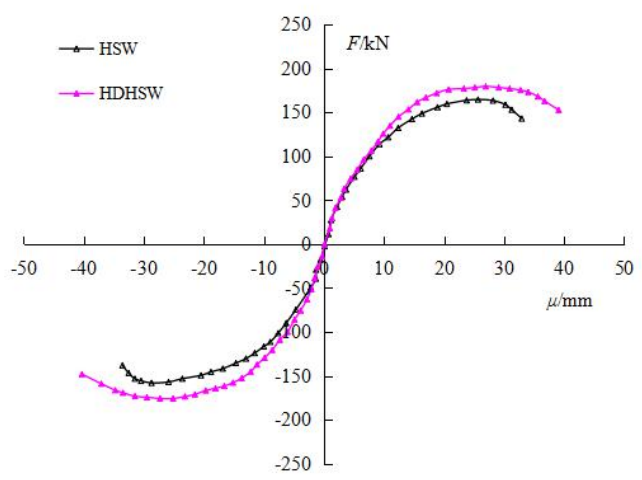

Fig.5. The contrast diagram of skeleton curves

\subsection{Analysis of energy dissipation capacity}

The equivalent viscous damping coefficient and the area enclosed by skeleton curve and the coordinate axis can be used as the indicator of the energy dissipation capacity. The equivalent viscous damping coefficient mainly reflects the satiation of the hysteretic curve; the area enclosed by skeleton curve and the coordinate axis reflects the structure of total energy dissipation. In this paper, two indicators are adopted to evaluate the energy dissipation capacity of shear walls. Figure 6 is the equivalent viscous damping coefficient-loading cycle curve. The mean area values are as the follows: the energy dissipation values of shear wall HSW, HDHSW are $4178.2 \mathrm{kN} \cdot \mathrm{mm}, 5697.9 \mathrm{kN} \cdot \mathrm{mm}$. Respectively, it's not difficult to figure out that the energy dissipation value of shear wall HDHSW with fiber-reinforced concrete has been increased by $36.4 \%$ than that of the common shear wall.

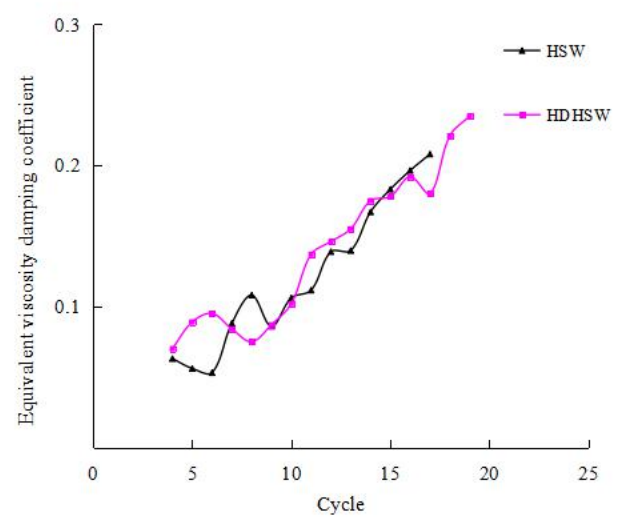

Fig.6. Equivalent hysteretic damping coefficient versus cycles

As can be seen from Figure 6, the equivalent viscous damping coefficient of the shear wall gains its increasing speed with the loading cycles. And the equivalent viscous damping coefficient of fiber-reinforced polymer concrete shear walls with concealed bracings is higher than that of ordinary shear walls under the same condition.

\subsection{Analysis of stiffness degradation}

The stiffness of shear walls in two stages can be seen in Tab.5. $K_{0}$ is the initial stiffness; $K_{\mathrm{c}}$ is the cracking stiffness; $K_{\mathrm{y}}$ is the yield stiffness; $\beta_{\mathrm{c} 0}$ is the stiffness attenuation from the initial stage to the cracking stage and $\beta_{\mathrm{y} 0}$ is the stiffness attenuation from the initial stage to the yield stage. In the initial stage, the stiffness of fiber reinforced polymer concrete shear wall HDHSW with concealed bracings is lower than that of ordinary shear wall HSW. But with the increase of displacement angle, its attenuation velocity is also slower than that of the latter, hence its stiffness in later stages is higher than that of HSW.

Tab.5 Experimental results of stiffness of specimens

\begin{tabular}{|c|c|c|c|}
\hline \multicolumn{2}{|c|}{ Sample number } & HSW & HDHSW \\
\hline$K_{0}$ & $\mathrm{kN} \cdot \mathrm{mm}^{-1}$ & 65.7 & 61.5 \\
\hline$K_{\mathrm{c}}$ & $\mathrm{kN} \cdot \mathrm{mm}^{-1}$ & 22.41 & 20.73 \\
\hline$K_{\mathrm{y}}$ & $\mathrm{kN} \cdot \mathrm{mm}^{-1}$ & 13.59 & 14.73 \\
\hline$\beta_{\mathrm{c} 0}$ & $K_{\mathrm{c}} / K_{0}$ & 0.34 & 0.34 \\
\hline$\beta_{\mathrm{y} 0}$ & $K_{\mathrm{y}} / K_{0}$ & 0.21 & 0.24 \\
\hline
\end{tabular}




\subsection{Analysis of damping property}

The ratios of frequency in the first stage to the modal damping were measured by hammering the two shear walls before and after the experiment. As the Tab.6 shows that in the elastic stage, fiber reinforced polymer modified concrete has an obvious effect on improving the damping capacity of shear wall, increasing by about $50 \%$ under the same conditions. Meanwhile, it can be seen from the frequency that although the fiber reinforced polymer concrete reduces the stiffness of shear walls in the initial stage, its stiffness in later stages is better than that of the ordinary concrete shear wall, which is favorable for earthquake resistance.

Tab.6.Variance of the frequency and damping ratio of undamaged and damaged specimens

\begin{tabular}{|c|c|c|c|}
\hline \multicolumn{2}{|c|}{ Sample number } & HSW & HDHSW1 \\
\hline \multirow{2}{*}{ Before the test } & Frequency/Hz & 139.1 & 134.2 \\
\cline { 2 - 4 } & Damping ratio\% & 3.1 & 4.6 \\
\hline \multirow{3}{*}{ After the test } & Frequency/Hz & 42.1 & 56.7 \\
\cline { 2 - 4 } & Damping ratio/\% & 8.7 & 11.4 \\
\hline
\end{tabular}

\section{CONCLUSIONS}

Through the experimental study and analysis of two different types of shear walls, conclusions can be drawn as follows:

(1) Polymer added in concrete can improve the brittleness of common concrete. Fiber -reinforced polymer concrete shear walls with concealed bracings has higher damping ratio, better ductility, greater cracking strength, stronger deformation capacity and better energy dissipation capacity.

(2) Compared with conventional shear walls, fiberreinforced polymer concrete shear walls with concealed bracings have wider scope of crack development. And when the walls are destroyed, the crushing area and damage is smaller; the stiffness is also higher at later stages.

This work was supported by University Science Research Project of Jiangsu Province(No.15KJB560014) and Ministry of Housing and Urban-Rural Development of China Research Project (No.2017-K9-010).

\section{References}

[1] Cao Wan-lin, Pang Guo-xin, et al. Studies of form and reasonable design of concealed bracings in R.C. shear walls [J]. Journal of Earthquake Engineering and Engineering Vibration, 2000, Vol.20,No.4:73 79 .

[2]Cao Wan-lin, Zhang Jian-wei, et al. Experimental study on seismic behavior of mid-rise RC shear wall with concealed bracings $[\mathrm{J}]$. Journal of Building Structures, 2002, Vol.23,No.6:26 32.

[3] Cao Wan-lin, Zhang Jian-wei, et al. Experimental study on seismic behavior of low rise double function $\mathrm{RC}$ shear wall with concealed bracings [J]. Journal of Building Structures, 2003, Vol.24,No.1:46 53 .

[4] ACI 318-02, "Building Code Requirements for Structural Concrete and Commentary", American Concrete Institute Committee 318, Farmington Hill, Michigan, U.S.A.(2002)

[5] Fu Xuli, Chung D D L. Vibration damping admixture for cement [J]. Cement and Concrete Research, 1996, Vol.26,69-75.

[6]Yoshihiko Ohama. Recent progress in concretepolymer composites[J].Advanced Cement Based Materials, 1997, 5(2):31-40

[7] Fu Xuli, Li Xiaohui and Chung D D L. Improving the vibration damping capacity of cement [J]. Materials Science, 1998 ,33:3601-3605.

[8] W.Cz.Wong, Ping Fang, J.K.Pan. Polymer effects on the vibration damping behavior of cement. Journal of Materals in Civil Engineering. ASCE, 2003,554-556.

[9] OU Jin-ping; GUAN Xin-chun. State-of-the-art of smart structural systems in civil engineering $[\mathrm{J}]$. Earthquake Engineering and Engineering Vibration. 1999 , (2) :21-28.

[10] WANG Meng-fu, SONG Xing-yu. Experimental research on damping property of High Damping Concrete Members [J]. Journal of vibration and shock, 2012,Vol,31(11):173-179. 